(Journal of Physical Science and Engineering]

\title{
Suseptibilitas Magnetik dan Kelimpahan Mineral Magnetik pada Tanah Sawah di Lawang dan Soekarno-Hatta, Malang
}

\begin{tabular}{l}
\hline Received \\
28 Februari 2018 \\
Revised \\
05 April 2018 \\
Accepted for Publication \\
06 April 2018 \\
Published \\
28 Februari 2020 \\
\hline
\end{tabular}

\author{
N Y Daryanti ${ }^{1 *}$, S Zulaikah ${ }^{1,2}$, N Mufti $^{1,2}$, dan D S Haryati ${ }^{1}$ \\ 1. Jurusan Fisika, Fakultas Matematika dan Ilmu Pengetahuan Alam, Universitas Negeri Malang, \\ Malang, 65115, Indonesia. \\ 2. Laboratorium Sentral Mineral dan Material Maju, Fakultas Matematika dan Ilmu Pengetahuan Alam, \\ Universitas Negeri Malang, Malang, 65115, Indonesia. \\ *E-mail: nurnuraininnur@gmail.com
}

\begin{abstract}
Paddy soil is a typical anthropogenic soils that has an important role throughout the world. Along with the development in urban area of Soekarno-Hatta Malang, paddy soils become switch function so many fields close to human activities. Efforts in understanding such environmental circumstances can be done by studying the properties of magnetic minerals contained in agricultural land or plantations. Magnetic properties are often used as indicators of the state and development of soils, especially to understand the magnetic and nonmagnetic properties of paddy soils. To fulfill the requirement, research of magnetic mineral properties of paddy soils in Lawang and Soekarno-Hatta, Malang. The result of this research is $\chi_{\text {lf }} 0,885-7,648 \times\left(10^{-6} \mathrm{~m}^{3} \mathrm{~kg}^{-1}\right)$. The elements that dominated on paddy soil such as $\mathrm{Fe}, \mathrm{Si}$, $\mathrm{Al}, \mathrm{Ca}$ with the lowest value is at $\mathrm{Ca}$ of $4,5 \%$ and which is the $\mathrm{Fe}$ element of $45,52 \%$.
\end{abstract}

Keywords: magnetic susceptibility, paddy soils, element of paddy soils.

\begin{abstract}
Abstrak
Tanah sawah merupakan tanah khas antropogenik yang memiliki peran penting di seluruh dunia. Seiring perkembangan pembangunan di wilayah perkotaan Soekarno-Hatta Malang, tanah sawah menjadi beralih fungsi sehingga tercipta lingkungan sawah yang berada dekat dengan aktivitas manusia. Hal tersebut berbeda dengan tanah sawah di Lawang. Upaya dalam memahami keadaan lingkungan seperti itu dapat dilakukan dengan mempelajari sifat mineral magnetik yang terkandung dalam tanah pertanian atau perkebunan. Sifat magnetik sering digunakan sebagai indikator keadaan lingkungan dan perkembangan tanah, terutama untuk memahami sifat magnetik dan non magnetik tanah sawah. Untuk memenuhi upaya tersebut dilakukanlah penelitian sifat mineral magnetik tanah sawah di Lawang dan Sokearno Hatta, Malang. Hasil penelitian diperoleh rentang nilai $\chi_{\mathrm{lf}} 0,885-7,648 \times\left(10^{-6} \mathrm{~m}^{3} \mathrm{~kg}^{-1}\right)$. Unsur yang mendominasi pada tanah sawah diantaranya $\mathrm{Fe}, \mathrm{Si}, \mathrm{Al}, \mathrm{Ca}$ dengan nilai terendah ada pada Ca sebesar 4,5\% dan yang tertinggi adalah unsur Fe sebesar 45,52\%.
\end{abstract}

Kata Kunci: suseptibilitas magnetik, tanah sawah, unsur tanah sawah.

\section{Pendahuluan}

Beberapa tipe tanah yang sangat dekat dengan kegiatan manusia diantaranya tanah kapur, tanah endapan, tanah pantai, dan tanah pertanian [1]. Tanah pertanian di Indonesia erat kaitannya dengan tanah padi atau sawah. Tanah sawah merupakan tanah khas antropogenik yang memiliki peran penting di seluruh dunia [2], tidak terkecuali di Indonesia. Tanah sawah yang selalu diolah dengan berbagai macam perlakuan dan limbah yang diperoleh aliran sungai maupun saat proses pengolahan, menyebabkan kandungan mineral tanah berbeda-beda [3].

Upaya dalam mengkaji tanah sawah dapat dilakukan dengan beberapa pendekatan, salah satunya ialah menggunakan metode kemagnetan batuan. Metode tersebut memahami sifat magnetik dari berbagai mineral magnetik dalam sedimen, batuan, serta tanah dan proses yang terlibat dalam 
pembentukannya [4]. Sifat magnetik sering digunakan sebagai indikator perkembangan tanah, terutama untuk identifikasi oksida besi tanah dan sifatnya [5]. Magnetisme juga dapat menjelaskan indikator pencemaran tanah dan perubahan iklim [6].

Perkembangan metode kemagnetan batuan salah satunya adalah memahami sifat magnetik di lingkungan sekitar aktivitas manusia [7]. Dalam penelitian ini metode kemagnetan batuan yang digunakan adalah agromagnetism yang mana fokus dalam mengkaji sifat magnetik di lingkungan pertanian dan perkebunan. Parameter magnetik yang digunakan dalam metode kemagnetan batuan ini adalah suseptibilitas magnetik. Hal ini karena secara kuantitatif keberadaan mineral magnetik dalam sedimen maupun tanah sangat kecil, namun cukup sensitif [8]. Suseptibilitas magnetik merupakan faktor pembanding antara magnetisasi $(M)$ dan medan magnet luar $(H)$. Sedangkan mineral magnetik merupakan mineral yang berasal dari unsur-unsur logam dalam tanah sawah.

Nilai suseptibilitas magnetik dapat digunakan untuk menentukan sifat mineral magnetik yang sering dikaitkan juga dengan persentase unsur besi yang terkandung didalamnnya [9]. Menentukan jumlah komposisi unsur besi dapat dilakukan dengan metode yang berbeda dari sebelumnya, yaitu metode non magnetik. Metode ini tidak menggunakan medan magnet ataupun magnetisasi sehingga unsur yang tidak memiliki sifat magnet juga terdeteksi. Mengetahui unsur juga membantu menentukan tingkat pencemaran logam dalam lahan pertanian atau perkebunan.

Beberapa lahan telah dilakukan penelitian seperti perkebunan apel di Pujon dan Poncokususmo [10], [11], lahan pertanian sawah di Madiun dan Malang khususnya Kepanjen [12]. Oleh karena itu perlunya penelitian lebih lanjut tentang tanah sawah yang memiliki perbedaan area geologi dan jarak aktivitas manusia. Hal ini dikarenakan mineral magnetik beberapa sedimen dan tanah dipengaruhi oleh lingkungan dan kondisi terbentuknya tanah. Dalam masing-masing lingkungan sedimen tanah terdapat kandungan mineral magnetik yang berbeda [13].

Tanah sawah pada umumnya jauh dari permukiman padat penduduk beserta aktivitasnya, namun hal ini berbeda dengan tanah sawah yang berada di Soekarno-Hatta Malang. Selain dekat dengan permukiman, aliran sungai irigasi dapat ditemukan sampah plastik dan juga adanya jalan yang sering dilalui kendaraan bermotor. Hal yang berbeda pada tanah sawah di Lawang, letak sawah cukup jauh dari permukiman dan aktivitas manusia, sehingga aliran sungai irigasi cenderung melimpah, jernih dan jarang ditemukan sampah plastik. Hal inilah menjadi poin penting untuk melakukan kajian awal mineral magnetik pada tanah sawah dengan kondisi yang berbeda.

Penelitian ini bertujuan mengetahui keadaan lingkungan dengan cara memahami sifat magnetik dan non magnetik pada lahan pertanian khususnya tanah sawah. Pemilihan tempat pengambilan sampel didasarkan pada letak dan jarak terhadap sumber kontaminan. Sifat magnetik dipelajari dengan uji suseptibilitas magnetik, sedangkan sifat non magnetik dipelajari melalui uji komposisi unsur dalam tanah sawah.

\section{Metode Penelitian}

\section{$2.1 \quad$ Pengambilan dan Preparasi Sampel}

Pengambilan sampel tanah sawah di Malang dengan luas sawah $\pm 1.142 \mathrm{Ha}$ area kota dan $\pm 45.888 \mathrm{Ha}$ area kabupaten. Letak geografis $112^{\circ} 17^{\prime} 10,90^{\prime \prime}-112^{\circ} 57^{\prime} 00^{\prime \prime}$ BT dan $7^{\circ} 44^{\prime} 55,11^{\prime \prime}-8^{\circ} 26 ’ 35,45^{\prime \prime}$ LS. Wilayah Malang yang juga dikelilingi oleh beberapa gunung berapi diantaranya Gunung Arjuno, Semeru, Kawi, dan Kelud. Pengambilan sampel tepatnya di wilayah kota yaitu kecamatan Lowokwaru daerah Soekarno-Hatta, untuk wilayah Kabupaten yaitu kecamatan Lawang. Pengambilan sampel di daerah Soekarno-Hatta tepatnya di kelurahan Mojolangu, dan daerah Lawang tepatnya berada di desa Turirejo. Titik pengambilan sampel dilakukan secara acak di setiap petak sawah dalam satu wilayah. Pengambilan sampel dilakukan pada setiap jarak minimal sekitar 3 meter.

Sampel yang diambil berupa tanah sawah basah atau lempung, berwarna kecokelatan serta banyak sisa-sisa batang padi sehingga tanah terasa berserat. Memberikan tata nama sampel sesuai dengan wilayah pengambilan, dimisalkan sampel dari wilayah Lawang diberikan nama LW. Begitu pula dengan sampel yang diambil pada area sawah yang lain yaitu tepatnya sawah berada di daerah Soekarno-Hatta maka kode sampel menjadi SH. Saat preparasi sampel, sampel tanah sawah yang berjumlah total 20 titik, setiap titik dibagi menjadi 2 sehingga satu titik LW atau SH menjadi LW 1.1 dan LW 1.2. Hal yang sama dilakukan pada sampel kode SH, dimisalkan SH 5.1 dan SH 5.2. 


\subsection{Karaterisasi Sampel}

Pengujian sampel dilakukan dengan metode kemagnetan batuan dengan sifat dari mineral magnetik alaminya baik dalam batuan, sedimen maupun tanah menjadi salah satu parameter magnetik yang akan dipelajari [14], [15]. Keberadaan mineral magnetik yang sedikit, cukup sensitif untuk mengetahui jumlah mineral magnetik yang terkandung, sehingga dilakukan uji suseptibilitas magnetik [8], [16]. Pengujian suseptibilitas magnetik dengan menggunakan susceptibility meter Bartington $M S 2 B$ di laboratorium mineral dan material maju Universitas Negeri Malang. Sensor alat tersebut menampilkan nilai volume suseptibilitas magnetik yang kemudian akan dihitung untuk mendapatkan nilai suseptibilitas magnetik dengan membaginya dengan volume sampel, yaitu $\chi=\kappa / \rho$. Uji suseptibilitas magnetik dilakukan dengan frekuensi rendah $0,46 \mathrm{~Hz}$ dan frekuensi tinggi 4,6 Hz [17], [18]. Pengukuran dengan frekuensi berbeda tersebut nantinya akan dimanfaatkan untuk menghitung nilai frekuensi dependen [9]. Karakterisasi selanjutnya untuk melihat unsur-unsur yang terdapat dalam tanah sawah menggunakan metode non magnetik yaitu uji XRF (X-Ray Fluoresence) [19]. Pengujian tersebut yang menampilkan jenis-jenis unsur yang terkandung dalam tanah sawah dalam nilai persentase.

\section{Hasil dan Pembahasan}

\subsection{Suseptibilitas Magnetik}

Nilai suseptibilitas magnetik pada tanah sawah di daerah Lawang dan Soekarno-Hatta memiliki rentang nilai yang bervariatif, hal ini dapat disebabkan oleh beberapa hal salah satunya ialah sumber atau dari mana mineral magnetik tersebut berasal. Adapun rentang nilainya mencakup rentang nilai suseptibilitas magnetik frekuensi rendah, tinggi, dan frekuensi dependen dalam persentase. Beberapa rentang nilai suseptibilitas magnetik sampel tanah sawah di beberapa titik yang diambil tertera dalam Tabel 1. Berdasarkan Tabel 1 rentang nilai suseptibilitas magnetik terendah terjadi pada sampel tanah dengan kode SH yaitu area sawah di Soekarno-Hatta dengan selisih rentang sebesar $2,7 \times 10^{-6}$. Rentang nilai suseptibilitas magnetik tertinggi berada pada sampel tanah sawah dengan kode LW yaitu pengambilan sampel area kecamatan Lawang. Selisih rentang nilai suseptibilitasnya sebesar 6,3 $\times 10^{-6}$. Adanya rentang yang tinggi ataupun rendah pada nilai suseptibilitas magnetik dapat disebakan oleh perbedaan jumlah distribusi mineral magnetik yang berada di dalam sampel [20] dan juga keadaan sekitar area pengambilan sampel serta penambahan material anthropogenic [21]. Di daerah Soekarno-Hatta area sawah dekat dengan permukiman, makam, jalan raya dan areanya sempit, sedangkan di daerah Lawang sawah luas dan jauh dari hiruk pikuk permukiman maupun kendaraan.

Dari data nilai suseptibilitas magnetik dapat dibuat plot grafik hubungan antara nilai $\chi_{\mathrm{lf}}$ dan $\chi_{\mathrm{fd}}$. Dengan nilai $\chi_{\text {If }}$ sebagai sumbu $x$ dan nilai $\chi_{\mathrm{fd}}$ sebagai sumbu $y$, grafik ini digunakan untuk melihat bagaimana korelasi antara $\chi_{\mathrm{lf}}$ dan $\chi_{\mathrm{fd}}$, yang diperlihatkan pada Gambar 1. Grafik tersebut menunjukkan sebagian besar nilai suseptibilitas sampel mengumpul pada area bawah, yaitu pada rentang nilai $\chi_{\text {lf }}$ $(0,885-7,648) \times 10^{-6} \mathrm{~m}^{3} \mathrm{~kg}^{-1}$ dan pada rentang nilai $\chi_{\mathrm{fd}}(0,260-2,339) \%$.

Grafik antara nilai $\chi_{\text {If }}$ dan $\chi_{\text {fd }}$ ini juga dapat digunakan untuk membedakan antara ukuran butir magnetik dan sebaran domain. Plot grafik ini mungkin juga memberikan pesan awal tentang klasifikasi sifat magnetik serta sumbernya. Melalui plot grafik pada Gambar 1 menunjukkan bahwa nilai $\chi_{\mathrm{fd}} \%<5 \%$ sehingga kumpulan butir magnetiknya didominasi oleh butir non SP. Nilai $\chi_{\text {If }}$ yang berada pada rentang nilai $(1-10) \times 10^{-6} \mathrm{~m}^{3} \mathrm{~kg}^{-1}$ menunjukkan bahwa jenis domain didominasi oleh SSD atau MD dengan sumber yang mungkin berasal dari pedogenesis, bakteri magnetosomes, autogenik atau biogenik Oleh karena itu terlihat dalam grafik hampir seluruh sampel memiliki domain butir magnetik stable single domain (SSD). 


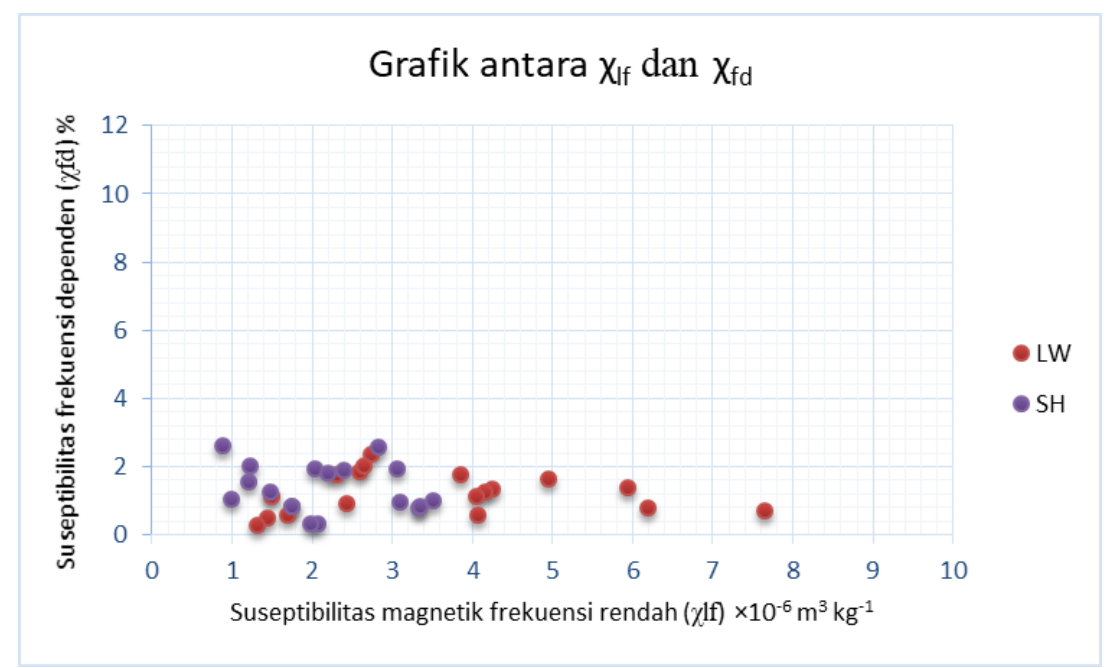

Gambar 1. Grafik antara nilai $\chi_{\mathrm{lf}}$ dan $\chi_{\mathrm{fd}}(\%)$

\subsection{Kelimpahan Mineral Magnetik}

Sampel tanah sawah yang diperoleh sebanyak 40 holder sampel dari 20 titik pengambilan. Setelah sampel telah diukur suseptibilitas magnetiknya kemudian segera dipreparasi untuk dilakukan pengujian XRF (X-Ray Fluoresence). Uji XRF dilakukan dengan tujuan mendapatkan komposisi unsur yang terkandung dalam tanah sawah, baik unsur magnetik maupun unsur non magnetik. Secara keseluruhan sampel yang telah diuji sebelumnya, kemudian dipilih 2 sampel untuk dilihat komposisinya. Sampel tanah dipilih dengan kriteria nilai suseptibilitas magnetik tertinggi dan terendah yang dapat dilihat melalui tabel rentang di atas (Tabel 1).

Kedua sampel yang terpilih untuk uji XRF ialah sampel dengan kode LW 5.2 dan SH 9.2 yang masing-masing memenuhi rentang nilai terendah dan tertinggi $\chi_{\text {If }}(0,885-7,648) \times 10^{-6} \mathrm{~m}^{3} \mathrm{~kg}^{-1}$. Kode sampel LW 5.2 yang memiliki nilai $\chi_{\text {If }} 7,648 \times 10^{-6} \mathrm{~m} 3 \mathrm{~kg}-1$, hal ini berarti nilai suseptibilitas tertinggi sedangkan kode sampel SH 9.2 memiliki nilai $0,885 \times 10^{-6} \mathrm{~m} 3 \mathrm{~kg}-1$, sehingga sampel ini yang mewakili nilai suseptibilitas terendah diantara sampel yang lain. Pada Tabel 2 menunjukkan hasil XRF dari kedua sampel.

Tabel 2 menyajikan hasil XRF dengan persentase komposisi unsur-unsur yang terkandung di dalam sampel tanah sawah. Dapat dilihat bahwa persentase terbesar adalah unsur besi (Fe) yaitu LW 5.2 sebesar 43,55\% dan SH 9.2 sebesar 40\%. Unsur selanjutnya yang memiliki nilai tinggi pada kode sampel LW 5.2 yaitu silika (Si) sebesar 35,9\%, aluminium (Al) sebesar 10\%, kalsium (Ca) sebesar $5,80 \%$, dan titanium (Ti) sebesar 1,99\%. Sama halnya dengan kode sampel SH 9.2 mulai dari Si, Al, $\mathrm{Ca}$, dan Ti secara berturut-turut 36,7\%; 9,9\%; 7,86\%; dan 2,09\%.

Hasil yang diperoleh juga menunjukkan banyak unsur non magnetik yang mendominasi tanah sawah. Unsur-unsur tersebut termasuk dalam unsur hara. Diantara unsur tersebut yaitu silika (Si), fosfor $(\mathrm{P})$, kalium $(\mathrm{K})$, dan kalsium $(\mathrm{Ca})$. Selebihnya banyak terdapat unsur magnetik dengan persentase terbesarnya didominasi oleh unsur besi (Fe), disusun aluminium (Al) dan titanium (Ti).

Tabel 1. Rentang nilai suseptibilitas magnetik tiap lahan sawah

\begin{tabular}{cccc}
\hline \multicolumn{4}{c}{ Rentang nilai suseptibilitas magnetik } \\
\hline $\begin{array}{c}\chi_{\mathrm{lf}} \\
\left(\times 10^{-6} \mathrm{~m} 3 \mathrm{~kg}-1\right)\end{array}$ & $\begin{array}{c}\mathrm{X}_{\mathrm{hf}} \\
\left(\times 10^{-6} \mathrm{~m} 3 \mathrm{~kg}-1\right)\end{array}$ & $\mathrm{X}_{\mathrm{fd}}(\%)$ \\
\hline $\mathrm{LW}$ & $1,320-7,648$ & $1,320-7,596$ & $0,260-2,339$ \\
$\mathrm{SH}$ & $0,885-3,506$ & $0,862-3,472$ & $0,302-2,627$ \\
\hline
\end{tabular}


Tabel 2. Komposisi unsur dalam tanah sawah

\begin{tabular}{lcc}
\hline \multirow{2}{*}{ Unsur } & \multicolumn{2}{c}{ Sampel Tanah Sawah } \\
\cline { 2 - 3 } & LW 5.2 (\%) & SH 9.2 (\%) \\
\hline $\mathrm{Al}$ & 10 & 9,9 \\
$\mathrm{Si}$ & 35,9 & 36,7 \\
$\mathrm{P}$ & - & 0,59 \\
$\mathrm{~K}$ & 0,78 & 0,86 \\
$\mathrm{Ca}$ & 5,80 & 7,86 \\
$\mathrm{Ti}$ & 1,99 & 2,09 \\
$\mathrm{~V}$ & 0,14 & 0,14 \\
$\mathrm{Cr}$ & 0,073 & 0,07 \\
$\mathrm{Mn}$ & 0,39 & 0,7 \\
$\mathrm{Fe}$ & 43,55 & 40 \\
$\mathrm{Cu}$ & 0,16 & 0,2 \\
$\mathrm{Zn}$ & 0,08 & 0,05 \\
$\mathrm{Eu}$ & 0,45 & 0,57 \\
$\mathrm{Re}$ & 0,2 & 0,3 \\
$\mathrm{~Pb}$ & - & - \\
$\mathrm{Ba}$ & 0,1 & - \\
\hline
\end{tabular}

Besarnya persentase unsur besi $(\mathrm{Fe})$ menandakan kelimpahan mineral magnetik dalam tanah sawah tersebut. Unsur-unsur tersebut diserap oleh tumbuhan padi untuk nutrisi pertumbuhannya, namun unsur magnetik diserap dengan komposisi yang sangat sedikit.

\section{Kesimpulan dan Saran}

\subsection{Kesimpulan}

Nilai suseptibilitas magnetik terbesar ada pada tanah sawah di daerah Lawang yaitu nilai $\chi_{\text {lf }}$ $7,648 \times 10^{-6} \mathrm{~m}^{3} \mathrm{~kg}^{-1}, \chi_{\mathrm{hf}} 7,596 \times 10^{-6} \mathrm{~m}^{3} \mathrm{~kg}^{-1}$ dan $\chi_{\mathrm{fd}} 2,339 \%$. Sebaliknya nilai terendah terdapat pada sampel tanah di sawah daerah Soekarno-Hatta dengan nilai $\chi_{\text {lf }} \quad 0,885 \times 10^{-6} \mathrm{~m}^{3} \mathrm{~kg}^{-1}, \quad \chi_{\mathrm{hf}}$ $0,862 \times 10^{-6} \mathrm{~m}^{3} \mathrm{~kg}^{-1}$ dan $\chi_{\mathrm{fd}} 0,302 \%$. Rentang nilai suseptibilitas magnetik terendah terjadi pada sampel tanah dengan kode SH yaitu area sawah di Soekarno-Hatta dengan selisih rentang sebesar $2,7 \times 10^{-6}$. Rentang nilai suseptibilitas magnetik tertinggi berada pada sampel tanah sawah dengan kode LW yaitu pengambilan sampel area kecamatan Lawang. Selisih rentang nilai suseptibilitasnya sebesar $6,3 \times 10^{-6}$. Adanya rentang yang tinggi ataupun rendah pada nilai suseptibilitas magnetik dapat disebakan oleh perbedaan jumlah distribusi mineral magnetik yang berada di dalam sampel dan juga keadaan lingkungan di area pengambilan sampel serta penambahan material anthropogenic, seperti unsur-unsur non magnetik.

Beberapa komposisi unsur mineral magnetik yang terdapat dalam tanah sawah diantaranya ada besi $(\mathrm{Fe})$, silika $(\mathrm{Si})$, aluminium $(\mathrm{Al})$, kalsium $(\mathrm{Ca})$, titanium $(\mathrm{Ti})$. Persentase terbesar yaitu besi $(\mathrm{Fe})$ 43,55\% untuk tanah sawah Lawang dan 40\% untuk tanah sawah Soekarno-Hatta. Unsur terbesarnya merupakan golongan unsur magnetik sehingga hal ini yang mungkin mengakibatkan adanya nilai suseptibilitas dalam tanah sawah. Nilai suseptibilitas yang fluktuatif di setiap titik juga dapat disebabkan oleh campuran unsur magnetik dan non magnetik dengan persentase komposisi yang berbeda-beda. Unsur magnetik maupun non magnetik dalam tanah termasuk dalam unsur hara yang diserap tumbuhan untuk proses pertumbuhannya. 


\subsection{Saran}

Pengkajian sifat magnetik tanah sawah perlu dilakukan secara menyeluruh dan intensif, mengingat bahwa sawah merupakan lahan istimewa dengan masa basah kering yang teratur. Selain itu juga tanah sawah memiliki peran penting bagi ketahan pangan bagi masyarakat, sehingga dari sifat magnetiknya dan mengetahuin unsur yang terkandung di dalamnya dalam mengendalikan dan menanggulangi pencemaran logam berat pada tanah sawah.

\section{Ucapan Terima Kasih}

Ucapan terima kasih disampaikan kepada semua pihak yang telah membantu dalam penyusunan naskah artikel.

\section{Daftar Rujukan}

[1] Y. Bian, T. Ouyang, Z. Zhu, N. Huang, H. Wan, dan M. Li, "Magnetic properties of agricultural soil in the Pearl River Delta, South China-Spatial distribution and influencing factor analysis," J. Appl. Geophys., vol. 107, hal. 36-44, 2014.

[2] G.-L. Zhang dan Z.-T. Gong, "Pedogenic evolution of paddy soils in different soil landscapes," Geoderma, vol. 115, no. 1-2, hal. 15-29, 2003.

[3] L. M. Chen, G. L. Zhang, D. G. Rossiter, dan Z. H. Cao, "Magnetic depletion and enhancement in the evolution of paddy and non- paddy soil chronosequences," Eur. J. Soil Sci., vol. 66, no. 5, hal. 886-897, 2015.

[4] E. K. Huliselan dan S. Bijaksana, "Identifikasi Mineral Magnetik pada Lindi (Leachate)," $J$. Geofis., vol. 2, 2007.

[5] J. Torrent, Q. S. Liu, dan V. Barrón, "Magnetic susceptibility changes in relation to pedogenesis in a Xeralf chronosequence in northwestern Spain," Eur. J. Soil Sci., vol. 61, no. 2, hal. 161-173, 2010.

[6] N. Jordanova, D. Jordanova, dan T. Tsacheva, "Application of magnetometry for delineation of anthropogenic pollution in areas covered by various soil types," Geoderma, vol. 144, no. 3-4, hal. 557-571, 2008.

[7] M. Evans dan F. Heller, Environmental magnetism: principles and applications of enviromagnetics, vol. 86. Academic press, 2003.

[8] S. Bijaksana, "Analisa Mineral Magnetik dalam Masalah Lingkungan," J. Geofis., vol. 1, hal. 19-27, 2002.

[9] J. Dearing, "Environmental magnetic susceptibility," Using Bartington MS2 Syst. Kenilworth Chi Publ, 1994.

[10] S. Zulaikah et al., "Pengukuran Resistivitas Dan Dielektrisitas Tanah Perkebunan Apel: Sebuah Langkah Awal Dalam Studi Agrogeophysics," Spektra J. Fis. Dan Apl., vol. 16, no. 1, hal. 5254, 2015.

[11] D. F. Rosanti, "KorelasiantaraSuseptibilitasMagnetikdenganUnsurLogamBeratpadaSekuensi Tanah di Pujon, Malang," SKRIPSI Jur. Fis.-Fak. MIPA UM, 2012.

[12] H. A. Niarta, "Studi Komparasi Suseptibilitas Magnetik, Kandungan Unsur, Morfologi Mineral Magnetik dan Keasaman Tanah Pertanian Padi di Madiun-Malang," SKRIPSI Jur. Fis.-Fak. MIPA UM, 2017.

[13] V. Gopikrishnan, R. Pazhanimurugan, T. Shanmugasundaram, M. Radhakrishnan, dan R. Balagurunathan, "Bioprospecting of actinobacteria from mangrove and estuarine sediments for antifouling compounds," Int. J. Innov. Res. Sci. Eng. Technol., vol. 2, no. 7, hal. 2726-2735, 2013.

[14] D. J. Dunlop, "Developments in rock magnetism," Rep. Prog. Phys., vol. 53, no. 6, hal. 707, 1990.

[15] D. Collinson, Methods in rock magnetism and palaeomagnetism: techniques and instrumentation. Springer Science \& Business Media, 2013.

[16] S. Bijaksana dan E. K. Huliselan, "Magnetic properties and heavy metal content of sanitary leachate sludge in two landfill sites near Bandung, Indonesia," Environ. Earth Sci., vol. 60, no. 2, hal. 409-419, 2010.

[17] M. Sarmast, M. H. Farpoor, dan I. E. Boroujeni, "Magnetic susceptibility of soils along a lithotoposequence in southeast Iran," Catena, vol. 156, hal. 252-262, 2017. 
[18] J. Yuan et al., "Characteristics of Loess Magnetic Susceptibility and Its Influencing Factors analysis in Hebei Country," in IOP Conference Series: Earth and Environmental Science, 2017, vol. 94, hal. 12114.

[19] W. R. Rohaeni, E. Supriadi, U. Susanto, dan T. D. Rosahdi, "Kandungan Fe dan Zn pada Beras Pecah Kulit dan Beras Sosoh dari Galur-Galur Padi Toleran Wereng Batang Cokelat," J. Ilmu Pertan. Indones., vol. 21, no. 3, hal. 172-176, 2017.

[20] L. T. Wahyuni, "Kajian Sifat Magnetik dan Kandungan Logam Berat pada Sedimen Mangrove Wonorejo Surabaya," SKRIPSI Jur. Fis.-Fak. MIPA UM, 2015.

[21] N. Kucer, I. Sabikoglu, dan N. Can, "Measurements of environmental pollution in industrial area using magnetic susceptibility method," Acta Phys. Pol.-Ser. Gen. Phys., vol. 121, no. 1, hal. 20, 2012. 